\title{
História do futebol em Divinópolis-MG: cavalheirismo e integração regional (1916-1930)
}

\author{
History of football in Divinópolis-MG: \\ chivalry and regional integration (1916-1930) \\ Daniel Venâncio de Oliveira Amaral \\ Universidade Federal de Minas Gerais (UFMG), Belo Horizonte / Brasil \\ Doutorando em Estudos do Lazer, UFMG (CAPES) \\ dvoamaral@gmail.com
}

\begin{abstract}
Resumo: Neste estudo, investigou-se, por meio da análise do corpo discursivo de periódicos, o desenvolvimento histórico da prática institucional do futebol na cidade de Divinópolis-MG, e os usos do jogo como via de integração regional dos sócios envolvidos com as comitivas esportivas, entre os anos de 1916 e 1930, período que corresponde à introdução e à difusão da modalidade esportiva no meio local. Além disso, buscou-se compreender a maneira com que o afloramento da competitividade, do pertencimento clubístico e a consolidação das primeiras rivalidades direcionaram os jogos de futebol na cidade e localidades adjacentes para uma série de incidentes e tensões sociais. Tais processos proporcionaram a esse esporte, no decorrer da década de 1920, novos sentidos e possibilitaram o florescimento de novos atributos ao campo esportivo.
\end{abstract}

Palavras-chave: História do futebol; História regional do Brasil; Oeste mineiro; Divinópolis.

\begin{abstract}
This study aims at investigating the historical development of the practice of football in the city of Divinópolis-MG, Brazil, through the years of 1916 and 1930. It is based on the analysis of local newspapers so as to comprehend the uses of the game as a means of regional integration of the members involved with this sport commissions, which correspond to the introduction and diffusion of the modality in the region. In addition, it aimed at understanding how the emergence of competitiveness, the sense of club belonging, and the consolidation of early rivalries led the football matches in the city and adjacent locations to a series of social tensions and incidents. Especially during the decade of 1920, such processes provided to the sport new meanings and enabled the emergence of new attributes to the field of sports.
\end{abstract}

Keywords: History of football; History of the regions of Brasil; Minas Gerais West; City of Divinópolis. 


\section{CONSIDERAÇõES INICIAIS ${ }^{1}$}

Nas duas últimas décadas, a academia brasileira produziu um volume significativo de pesquisas históricas sobre o desenvolvimento dos esportes em importantes cidades do país, como Rio de Janeiro, São Paulo, Santos, Belo Horizonte, Porto Alegre, Florianópolis, Salvador, Recife e Natal. ${ }^{2}$ No entanto, as investigações estão majoritariamente concentradas nos centros urbanos mais proeminentes, ao passo que articulações interpretativas sobre a gênese histórica de tais práticas em localidades do interior brasileiro esbarram ainda no limitado número de trabalhos historiográficos. ${ }^{3}$

Sobre o Oeste de Minas Gerais, região que, no início da década de 1920, constituía-se de 27 municípios, ${ }^{4}$ dos quais apenas dois contavam na sede com uma população urbana superior a cinco mil habitantes, ${ }^{5}$ são raros os trabalhos que incorporam o futebol como objeto de investigação histórica. Excetuando as cidades de São João del-Rei e Oliveira, que nos últimos anos receberam, sob diferentes ângulos, análises do período embrionário do futebol, ${ }^{6}$ as demais cidades, vilas e distritos da região Oeste de Minas Gerais não foram alvo de investigações acerca das particularidades presentes no espraiamento de práticas esportivas pelos sertões brasileiros.

Um exemplo dessa constatação é a cidade de Divinópolis que, no ano de 1920, contava com uma população de apenas 10.305 moradores, distribuídos entre as áreas rurais e o tímido núcleo urbano, este último constituído de 35

\footnotetext{
${ }^{1}$ Este artigo é uma versão ampliada e revista de parte da dissertação de mestrado, defendida em abril de 2016 no Programa de Pós-Graduação em História da Universidade Federal de São João del-Rei, intitulada "À mania intoxicadora: introdução clubística e consolidação dos sentidos de competitividade do foot-ball no centro-oeste mineiro (1888-1930)". A pesquisa recebeu apoio financeiro da UFSJ.

${ }^{2}$ Ver os artigos da coletânea, MELO (org.). Os sports e as cidades brasileiras.

${ }^{3}$ DIAS; NETO; SILVA; MAYOR. História do futebol em Minas Gerais.

${ }^{4}$ Segundo o relatório de finanças de Minas Gerais, referente ao ano de 1922, os 27 municípios que compunham o Oeste mineiro eram: Abaeté, Bambuí, Bom Despacho, Bom Sucesso, Campo Belo, Carmo do Paranaíba, Cláudio, Divinópolis, Dores do Indaiá, Formiga, Itapecerica, Itaúna, Lagoa Dourada, Oliveira, Pará de Minas, Passa Tempo, Patos, Pequi, Perdões, Pitangui, Piumhi, Prados, Resende Costa, Santo Antônio do Monte, São Gotardo, São João del-Rei e Tiradentes. Cf. MINAS GERAIS. Relatório apresentado ao Exmo. 5r. Dr. Raul Soares de Moura, p. 371-373.

${ }^{5}$ Esses dois municípios são: São João del-Rei, com 10.321 moradores urbanos, e Formiga, com 6.120 moradores urbanos. Cf. MINAS GERAIS. Annuario estatistico: anno I (1921), v. II, p. 847, 929.

6 Cf. AMARAL; COUTO. "Um festin obsceno": pertencimento clubístico e expansão socioespacial do foot-ball em Oliveira-MG (1920-1930); LIMA. Trilhas históricas do Foot-Ball em São João del-Rei; COUTO; SILVA. Circularidade cultural e modernização dos hábitos.
} 
logradouros, sem serviços de calçamento e de arborização. ${ }^{7}$ Nesse mesmo ano, quase $70 \%$ da população de Divinópolis residia em pequenos povoados rurais, tais como "Branquinhos, Cachoeirinha, Cacoco, Cemitério, Choro, Costas, Ferrador, Fortaleza, Gafanhoto, Guryta, Mata, Pary, Usina de Cachoeira e Vazes”, que movimentaram, em 1919, 508 estabelecimentos rurais produtores de diferentes itens agrícolas, e um rebanho de 20.583 cabeças de gado e aves. Não por acaso, $64 \%$ da mão de obra da cidade que trabalhava de forma remunerada e declarava sua profissão estava empregada na "exploração do solo".8 Todos esses dados revelam o caráter acentuadamente rural da vida em Divinópolis naquela época. De outra parte, contrariando uma das principais prerrogativas da historiografia especializada nos esportes, que aponta a urbanização e o crescimento das cidades como os principais vetores explicativos dessas práticas, ${ }^{9}$ Divinópolis, mesmo apresentando uma estrutura de predomínio rural e de baixa densidade demográfica, desenvolveu sociabilidades ligadas aos esportes, mais especificamente, ao futebol. Tal modalidade, pioneira desse gênero de divertimento, desempenhou um papel de destaque nas vivências cotidianas da cidade, aglutinando sócios aos clubes, autoridades políticas e aficionados pelo esporte.

Assim, este trabalho visa compreender o desenvolvimento histórico da prática institucional do futebol na cidade de Divinópolis, MG, e os usos desse esporte como via de integração regional dos sócios envolvidos com as comitivas esportivas, entre os anos de 1916 e 1930, período que corresponde à introdução e à difusão da modalidade no meio local. Buscou-se, então, compreender, mais especificamente, de que maneira o acirramento da competitividade, do pertencimento clubístico e a consolidação das primeiras rivalidades direcionaram os jogos de futebol na cidade e localidades a ela adjacentes a uma série de incidentes e tensões sociais. Tais processos proporcionaram à modalidade, no decorrer da década de 1920, novos sentidos e possibilitaram o desenvolvimento de novos atributos ao campo esportivo.

\footnotetext{
${ }^{7}$ MINAS GERAIS. Annuario estatistico: anno I (1921), v. IV, p. 50.

${ }^{8}$ Ver AMARAL; DIAS. Nos trilhos do lazer: entretenimento urbano e mercado de diversões em Divinópolis, Minas Gerais, 1890-1920.

${ }^{9}$ Ver DIAS, Cleber. Esporte e cidade: balanços e perspectivas.
} 
A principal fonte desta pesquisa é um conjunto de periódicos formado por exemplares dos jornais Divinopolis (1916-1918), A Estrella da Oeste (1922-1928) e A Pena (1926-1934). De forma acessória, consultou-se também os jornais Folha de Minas (1916), O Reformador (1920) e Oeste Mineiro (1922-1923), todos publicados em Divinópolis e com apenas alguns exemplares disponíveis. Apesar de preservadas, às vezes de modo irregular, essas fontes jornalísticas constituem-se como os principais registros de imprensa, em que ficaram notados aspectos diversos da história dessas sociedades e do campo esportivo da região naquela época. Alguns exemplares da Gazeta de Minas, que era publicada na vizinha cidade de Oliveira, bem como documentos produzidos pelo poder público municipal e estadual também foram consultados para que se pudesse cotejar as informações. Por meio da análise do corpo discursivo das fontes históricas, foi possível desvelar, especialmente no campo esportivo, as múltiplas articulações sociais promovidas pelos jogos de futebol em Divinópolis, sobretudo na ocasião de encontros intermunicipais e os novos atributos sociais adquiridos pelo jogo, impulsionados pela sua difusão espacial por diversas cidades, vilas e distritos do Oeste mineiro.

\section{UM ESPORTE FIDALGO EM DIVINÓPOLIS}

Em agosto de 1916, a imprensa de Divinópolis registrou as primeiras atividades promovidas pelos sócios da recém-fundada comitiva esportiva do Divinopolis Foot Ball Club, no improvisado campo da Praça Municipal.10 A partir de então, os "ensaios" do novato clube passaram a ser realizados conjuntamente a alguns convites, impressos em pequenas colunas nos periódicos locais, direcionados a "todas as famílias" e ao "público em geral",11 o que demonstra a possibilidade de que os envolvidos extracampo com a modalidade fossem pessoas de vários estratos sociais.

No entanto, se, fora das quatro linhas, como se diz no jargão do futebol, havia uma abertura para que agentes pertencentes às classes menos abastadas pudessem se envolver com o divertimento, o mesmo não se pode dizer sobre aqueles que praticavam o jogo. Apesar de não haver disponível para consulta os

\footnotetext{
${ }_{10}^{10}$ DIVINOPOLIS. Divinópolis, p. 4, 27 agosto 1916.

${ }^{11}$ DIVINOPOLIS. Divinópolis, p. 3, 17 setembro 1916.
} 
estatutos do clube assinados em 29 de julho de 1917,12 a destacada posição social de seus principais sócios evidencia a presença de algumas restrições, que foram decisivas para que, inicialmente, o clube contasse apenas com membros da alta sociedade divinopolitana. De tais agentes podem-se destacar: Pedro Xavier Gontijo (farmacêutico),13 Machado Gontijo (cirurgião dentista), ${ }^{14}$ Pedro Guerra da Silva (coletor estadual de impostos) ${ }^{15}$ e Mariano Biondini (filho do comerciante Achili Biondini, proprietário da Sapataria Norte Americana). ${ }^{16}$ O perfil social refinado de seus sócios garantiu que tal grupo mantivesse, inicialmente, o monopólio da prática institucional do foot-ball ${ }^{17}$ na cidade.

Longe de ocorrer como um processo exclusivo da cidade de Divinópolis, o jogo de bola, nos últimos anos da década de 1910, espraiava-se no meio de grupos mais abastados de diversos outros pequenos núcleos do Oeste mineiro. Por meio de informações extraídas do anuário estatístico de Minas Gerais do ano de 1921, constatamos que localidades diversas das circunvizinhanças de Divinópolis, como Itaúna (1915), Oliveira (1916), Bom Sucesso (1917), Itapecerica (1918), Carmo do Cajuru (1919), Pitangui (1919) e Santo Antônio do Monte (1920) também vivenciaram a emergência da prática institucional do fenômeno futebolístico. ${ }^{18}$ No meio dessa profusão de comitivas esportivas, os jogos de foot-ball, sobretudo na ocasião de encontros intermunicipais, configuraram-se como importante instrumento para favorecer a abertura de vias de aproximação social e política entre os agentes das classes hegemônicas que compunham o quadro de sócios das comitivas esportivas.

Em fevereiro de 1917, a diretoria do Oliveira Sport Club, da cidade de Oliveira, enviou um convite ao clube Divinopolis para a realização de uma disputa intermunicipal no Prado Municipal daquela localidade. ${ }^{19} \mathrm{Na}$ manhã do dia 11, os divinopolitanos foram

\footnotetext{
12 DIVINOPOLIS. Divinópolis, p. 1, 29 julho 1917.

${ }^{13}$ FOLHA DE MINAS. Divinópolis, p. 3, 19 março 1916.

${ }_{14}^{14}$ FOLHA DE MINAS. Divinópolis, p. 4, 19 março 1916.

15 DIVINOPOLIS. Divinópolis, p. 5, 21 maio 1916.

${ }^{16}$ FOLHA DE MINAS. Divinópolis, p. 3, 19 março 1916.

17 Doravante, o termo futebol e os nomes das comitivas esportivas serão escritos conforme a ortografia da época.

${ }^{18}$ As comitivas esportivas fundadas nas respectivas localidades foram: Itaúna Foot-Ball Club; Oliveira Sport Club; Bom Sucesso Foot-Ball Club; São Bento Foot-Ball Club; Cajuru Foot-Ball Club; Pitanguy Foot-Ball Club e Tiradentes Foot-Ball Club. Cf. MINAS GERAIS. Annuario estatistico: anno I (1921), v. IV, p. 433-438.

${ }^{19}$ DIVINOPOLIS. Divinópolis, p. 1, 9 fevereiro 1917.
} 
recebidos na estação ferroviária de Oliveira sob o espocar de fogos e ao som de uma banda de música. As festividades promovidas pelos anfitriões oliveirenses após a partida foram descritas por um cronista da imprensa de Divinópolis:

\begin{abstract}
No meio das mais impetuosas manifestações de entusiasmo e alegria, dirigiramse ao hotel, onde lhes foi servido uma lauta mesa, tendo-se ouvido nessa ocasião, uma vibrante saudação pelo inteligente moço dr. José A. Trindade, que leu uma bela peça literária e social, terminando num amistoso brinde ao Divinopolis F. C., em que foi respondido num discurso cheio de apropriados pedaços históricos e de agradecimento pelo Dr. Recém-vindo M. Gontijo. Em seguida ao banquete, a convite do Oliveira S. C., os players divinopolitanos, dirigiram-se ao Cinema Oliveirense, onde lhes foi oferecida, em homenagem, uma empolgante e animada batalha de confete e lança perfume. ${ }^{20}$
\end{abstract}

No dia seguinte, a delegação divinopolitana promoveu um evento no Teatro Divinópolis, que contou com a presença do Coronel Manuel Antônio Xavier, ${ }^{21}$ uma das figuras mais influentes do cenário político de Oliveira:

No Teatro Divinópolis, onde também se encontrava o distinto Cel. Manuel A. Xavier, foi servido aos presentes, um copo de cerveja. Fez-se ouvir o farmacêutico Pedro X. Gontijo, que cumprimentou os moços jogadores em nome do povo divinopolitano. Respondeu-lhe desvanecidamente o orador do club, Dr. Recém-vindo Gontijo, que expôs os episódios da luta em Oliveira, enaltecendo o valor dos oliveirenses, e terminando com um viva a sociedade oliveirense na pessoa do Cel. Xavier, sendo agradecido em eloquentes palavras. ${ }^{22}$

0 registro da partida realizada na cidade de Oliveira revela toda pompa e fidalguia que permeava os eventos intermunicipais organizados por sócios de comitivas futebolísticas. Fogos, bandas de música, hospedagem em hotéis, bailes e outras festividades são alguns dos cerimoniais que transformavam encontros esportivos em eventos sociais de destaque. Nesses termos, o foot-ball para além do seu caráter esportivo, ao congregar autoridades políticas e agentes das classes mais abastadas, adquiria a capacidade de promover redes de sociabilidades e de cooperação política entre os sócios e as localidades envolvidas com o jogo.

\footnotetext{
${ }^{20}$ DIVINOPOLIS. Divinópolis, p. 3, 18 fevereiro 1917.

21 O Coronel Manuel Antônio Xavier ocupou, entre os anos de 1912-1915, o cargo de Presidente da Câmara Municipal de Oliveira. Em 1916, foi nomeado pela Secretaria da Agricultura para o levantamento da estatística nos municípios de Oliveira, Passa Tempo, Cláudio, Itapecerica, Divinópolis, Santo Antônio do Monte, Bom Despacho, Dores do Indaiá, e Abaeté. GAZETA DE MINAS. Oliveira, p. 1, 14 maio 1916.

${ }^{22}$ DIVINOPOLIS. Divinópolis, p. 3, 18 fevereiro 1917.
} 
Após a disputa na cidade de Oliveira, os sócios do clube Divinopolis, buscando maior desenvolvimento institucional da modalidade entre os seus aficionados, logo se movimentaram para a construção de uma praça de esportes que pudesse apresentar condições para o recebimento de comitivas das suas adjacências. ${ }^{23}$ Não por acaso, uma das primeiras medidas tomadas pelos sócios, após a inauguração do "belo e pitoresco" campo em junho de 1917,24 foi o envio de um convite aos sócios do Oliveira Sport Club, para a realização de um encontro intermunicipal no recém-inaugurado campo de foot-ball. ${ }^{25}$ Apesar de a disputa não ter ocorrido em função da dissolução do clube Oliveira, ${ }^{26}$ um baile organizado pelos anfitriões divinopolitanos, no intuito de receber a delegação da vizinha localidade, evidenciou como os jogos de foot-ball aos poucos se afirmavam como um importante instrumento para favorecer processos de sociabilidades entre os grupos envolvidos com comitivas esportivas:

\section{A elite Divinopolitana prepara, para o dia 15 do mês vindouro, um baile a ser oferecido ao Oliveira Sport Club que nesse dia disputará nessa cidade o seu primeiro match com o nosso Divinopolis Foot Ball Club. 0 sarau terá lugar no sobrado, antigo escritório da Empresa Gabaglia. ${ }^{27}$}

A partir de fevereiro de 1918, não foram encontradas mais informações sobre o foot-ball em Divinópolis, em virtude da extinção das edições do único periódico local disponível para consulta nesse ano - a última edição desse periódico data do dia 17 de fevereiro de 1918. Apenas em setembro de 1922, com a possibilidade de consulta ao jornal $A$ Estrella da Oeste, voltamos a encontrar notícias envolvendo os encontros futebolísticos. Todavia, convém ressaltar que, mesmo com o desaparecimento de informações sobre o fenômeno esportivo entre os anos de 1918 e 1922, em função da falta de fontes primárias, não significa que o esporte tenha deixado de ser desenvolvido pelos sportmen de Divinópolis. Uma pequena nota referente ao aniversário de um atleta ligado ao clube Divinopolis, veiculada pelo periódico Reformador, do qual há apenas duas de suas edições disponíveis, sinaliza para o fato do Divinopolis Foot Ball Club ter permanecido com

\footnotetext{
${ }^{23}$ DIVINOPOLIS. Divinópolis, p. 1, 6 maio. 1917.

${ }^{24}$ DIVINOPOLIS. Divinópolis, p. 1, 14 junho 1917.

25 DIVINOPOLIS. Divinópolis, p. 1, 29 julho 1917.

26 DIVINOPOLIS. Divinópolis, p. 2, 4 novembro 1917.

27 DIVINOPOLIS. Divinópolis, p. 3, 28 outubro 1917.
} 
suas atividades na virada da década de 1920: "Fez anos no dia 13 do corrente o jovem sportman Amarildo, destemido goal-kiper do Divinopolis Foot Ball Club que foi muito visitado e cumprimentado pelos seus numerosos amigos". 28

No ano de 1922, o cenário urbano da cidade passou a contar com uma nova comitiva esportiva, dando mostras de como o jogo, inicialmente praticado no interior de um seleto grupo, expandia-se entre os sportmen locais. 0 primeiro relato da nova comitiva foi encontrado no mês de setembro quando a imprensa descreveu uma partida realizada entre o Oeste Foot Ball Club e o Divinopolis Foot Ball Club, partida que foi vencida pelo Oeste pelo placar de $4 \times 0 .{ }^{29}$

Mesmo que os periódicos não ofereçam muitos detalhes sobre a fundação e o quadro de sócios do novato Oeste, acredita-se que se tratava de uma comitiva constituída por elementos ligados à Estrada de Ferro Oeste de Minas, uma vez que a cidade sediava um entroncamento ferroviário com direção ao Rio de Janeiro, Belo Horizonte, São Paulo, Vitória e Goiás, uma grande oficina ferroviária e uma Vila Operária. ${ }^{30}$ Assim, a escolha do nome Oeste para a comitiva, sinaliza para uma aproximação entre funcionários da ferrovia e o foot-ball, sugerindo que houve uma ampliação social da institucionalização do jogo. Tal difusão social fica ainda mais nítida quando observamos que o primeiro encontro intermunicipal realizado pelo clube Oeste foi contra um clube de operários da cidade de Oliveira. Em novembro de 1922, os sócios do Operario Foot Ball Club desembarcaram em Divinópolis para participarem dos festejos de instalação do termo judiciário, que teve o jogo entre o clube Oeste e o clube Operario como uma de suas atrações. ${ }^{31}$

Não obstante, a difusão social do jogo logo gerou movimentação mais efetiva por parte dos seletos sportmen da cidade, que, buscando manter as rédeas do controle institucional da modalidade, promoveram, no dia 12 de março de 1923, uma reunião na residência do Sr. João Baptista de Siqueira, com o intuito de realizar a junção dos dois clubes esportivos:

\footnotetext{
${ }^{28}$ O REFORMADOR. Divinópolis, p. 3, 18 janeiro 1920.

${ }^{29}$ A ESTRELLA DA OESTE. Divinópolis, p. 1, 24 setembro 1922.

${ }^{30}$ Sobre a chegada da Estrada de Ferro Oeste de Minas em Divinópolis, ver CORGOZINHO. Nas linhas da modernidade.

${ }^{31}$ A ESTRELLA DA OESTE. Divinópolis, p. 2, 22 outubro 1922.
} 
Presidiu a reunião Sr. Carlos Chula, que usando a palavra fez sentir a necessidade de união dos clubs locais, para o bem estar e desenvolvimento do sportismo, nesta cidade, propondo para adotarem o nome de União Foot Ball Club o que foi aprovado por unanimidade de votos. ${ }^{32}$

Apesar de a reunião ser presidida por Carlos Chula, funcionário da Estrada de Ferro Oeste de Minas, que trabalhava no setor de iluminação dos carros, ${ }^{33}$ cabe destacar que Chula era um agente de grande destaque que, além de ser empresário do conjunto artístico Centro Teatral Divinópolis, ${ }^{34}$ participava ativamente do carnaval local, ocupando o posto de vice-presidente da sociedade carnavalesca "Cordão Catalão". ${ }^{35}$ Outros agentes de destaque, como Deodolino Antonio Souza (segundo escrivão do judiciário), ${ }^{36}$ Irineu Lisbôa (médico e chefe do posto de profilaxia do município), ${ }^{37}$ Alypio Goulart (advogado), ${ }^{38}$ Mario Cassanta (advogado) ${ }^{39}$ e Ataliba Lago (jornalista), ${ }^{40}$ somando-se a muitos remanescentes dos primeiros sportmen, como Mariano Biondini, Jose Polycarpo e Pedro Xavier Gontijo, tomaram o ensejo de refinar o quadro de sócios da nova comitiva.

Após a fundação do clube, o corpo de sócios logo buscou sua inserção nos eventos intermunicipais que reuniam as altas rodas. Em maio de 1923, partia de Divinópolis para a cidade de Santo Antônio do Monte um "especial comboio" com onze jogadores, a banda de música Lira Oeste e inúmeras pessoas da "High-Life divinopolitana". Na ocasião, seria realizado o match amistoso entre o União Foot Ball Club e o Tiradentes Foot Ball Club. A partida foi marcada pelos mesmos cerimoniais pomposos que possibilitavam o estreitamente de laços entre os envolvidos institucionalmente com o jogo. Um cronista divinopolitano que cobriu o evento publicou uma nota, enfatizando as relações de aproximação proporcionadas pelo embate futebolístico:

Deram início ao jogo e depois de uma luta terrível, tiveram que dar por terminado o encontro que acabou debaixo de um temporal ameaçador, fazendo o Tiradentes 2 para 4 do nosso União, o aclamado vencedor daquele prélio desportivo.

\footnotetext{
${ }^{32}$ A ESTRELLA DA OESTE. Divinópolis, p. 3, 14 março 1923.

${ }^{33}$ Cf. RAPOSO. Dicionário dos construtores de Divinópolis, p. 34.

${ }^{34}$ A ESTRELLA DA OESTE. Divinópolis, p. 3, 19 outubro 1924.

${ }^{35}$ A ESTRELLA DA OESTE. Divinópolis, p. 2, 15 março 1925.

${ }^{36}$ A ESTRELLA DA OESTE. Divinópolis, p. 1, 1 outubro 1922.

${ }^{37}$ A ESTRELLA DA OESTE. Divinópolis, p. 3, 15 abril 1923.

${ }^{38}$ A ESTRELLA DA OESTE. Divinópolis, p. 3, 1 julho 1923.

${ }^{39}$ A ESTRELLA DA OESTE. Divinópolis, p. 3, 30 setembro 1923.

${ }^{40}$ A ESTRELLA DA OESTE. Divinópolis, p. 2, 4 maio 1924.
} 
Voltaram novamente a casa, onde trocaram as suas roupas, e seguiram para o Restaurante da Estação sendo servido um magnífico banquete, falando o Sr. Dr. Lucio Ramos, que em altissonante linguagem fez uma boa síntese do foot-ball, cultuado para o necessário desenvolvimento físico da mocidade de agora.

Respondeu o Dr. Irineu Lisbôa agradecendo em nome dos presentes divinopolitanos que ali se achavam, como no de nossa cidade que ora se sente alegre na pessoa de seus filhos.

Feito isso, partiu o especial de regresso a nossa Divinópolis, 4 horas e 50 da tarde, deixando da plataforma do carro, o Sr. Sertório de Moraes as suas últimas palavras de agradecimento com o modo com que nos recebeu aquele amável povo de Santo Antônio do Monte.

De resto, somos forçados a dizer: - aquela gente é tão boa, tão gentil, tão amável repito, que parece, se não é certo, cada divinopolitano trouxe em seu coração, traços indeléveis de saudade. ${ }^{41}$

Dois meses após visitarem a cidade de Santo Antônio do Monte, os sócios do clube União receberam a visita de um "team de foot ball" da capital Belo Horizonte. ${ }^{42}$ No dia 28 de julho de 1923, os sportmen da capital mineira foram recepcionados pela diretoria do clube União na estação ferroviária, com fogos e uma banda de música, realizando, antes de seguirem para o campo, um passeio pelas ruas centrais da cidade. A partida teve como árbitro o Sr. Carlos Chula, vice-presidente do clube União, cuja "camaradagem" para com os visitantes foi alvo de comentários da imprensa local:

A atuação do Sr. Carlos Chula merece um comentário. Em todo o decorrer do jogo, o "Paina" embora seja vice-presidente do União, protegeu escandalosamente os belorizontinos.

Dois "pênaltis" visíveis dos visitantes, com a admiração de todos, redundaram em dois "hands" contra os locais!!

Se não fosse a sua "camaradagem", talvez o nosso "score" fosse de uma "meia dúzia a fubá" - como se diz na gíria do sport.43

Esse registro, notoriamente, explicita o caráter apenas secundário da competitividade do jogo, especialmente na ocasião de encontros intermunicipais. A visita ou o recebimento de uma comitiva esportiva exigia dos sportmen um comportamento advindo do repertório da cortesia fidalga, uma vez que o foot-ball era usado como veículo de aproximação e de estreitamento de laços entre sócios e localidades. Assim, as comitivas serviam como uma espécie de embaixada diplomática, com a função de promover a integração dos sócios, o que enfraquecia a necessidade da vitória esportiva e o afloramento das rivalidades. Em junho de

\footnotetext{
${ }^{41}$ A ESTRELLA DA OESTE. Divinópolis, p. 3, 20 maio 1923.

${ }^{42}$ O POPULAR. Divinópolis, p. 1, 26 junho 1923.

${ }^{43}$ A ESTRELLA DA OESTE. Divinópolis, p. 5, 29 julho 1923.
} 
1924, por exemplo, nas comemorações do $12^{\circ}$ aniversário de emancipação política de Divinópolis, as festividades organizadas pelas principais lideranças políticas locais contaram com a participação da comitiva do Pitanguy Foot Ball Club, da cidade de Pitangui, que foi recebida pelos sócios do clube União com toda a pompa que acompanhava a disputa dos encontros intermunicipais. ${ }^{44} \mathrm{Na}$ cobertura do evento, um cronista do jornal $A$ Estrella da Oeste deixou transparecer que, além do jogo esportivo que fazia parte das comemorações, uma das atribuições da "embaixada da amizade" da cidade Pitangui, foi representar politicamente aquela cidade nos festejos municipais:

\begin{abstract}
Domingo último, dia que marcou o $12^{\circ}$ aniversário da nossa emancipação política, Divinópolis teve a inefável satisfação de acolher em seu seio a nobre embaixada da lendária Pitangui, que em um gesto de cavalheirismo, o mais requintado quis compartilhar a nossa justa alegria, e patentear-nos a sua estima. Nossa terra sente-se sobremaneira desvanecida pela distinção que acaba de receber, distinção que contribuirá para que ela se encha cada vez mais, daquele orgulho nobre e santo que incentiva o progresso dos povos, daquele orgulho nobre e santo de só querer aquilo que é belo, que é grandioso, que é sublime. Pitangui por seus ilustres embaixadores, visitou Divinópolis como a irmã querida, que festeja um acontecimento feliz, vindo trazer-lhe num abraço amigo, a segurança de seu apoio, a demonstração viva de seu carinho [...] a Divinópolis agradecida, enfim, estende os braços e aperta bem contra o coração, a sua velha amiga, a grande e lendária Pitangui. ${ }^{45}$
\end{abstract}

Por conseguinte, todas essas relações de aproximação narradas por cronistas da imprensa, que faziam do foot-ball veículo de integração dos sócios, foram se diluindo em função dos novos atributos que o jogo cortês e cavalheiresco incorporava. Em meados da década de 1920, os cronistas que cobriam os encontros amistosos que permeavam as narrativas das primeiras disputas, gradativamente, foram se deparando com o afloramento dos predicados referentes à valorização da vitória esportiva, motivados pela difusão espacial do jogo, pela dinamização do interesse dos "assistentes" e, consequentemente, pelas paixões clubísticas. Tais predicados já estavam presentes, pelo menos desde o início da década de 1910, nos jogos e competições de outros centros do país, como Rio de Janeiro e Belo Horizonte, e eram recorrentes reações extravagantes por parte dos partidários das equipes, algumas se desdobrando em brigas, confusões e "sururus". 46

\footnotetext{
${ }_{44}^{44}$ A ESTRELLA DA OESTE. Divinópolis, p. 3, 8 junho. 1924.

${ }^{45}$ A ESTRELLA DA OESTE. Divinópolis, p. 1, 8 junho 1924.

${ }^{46}$ PEREIRA. Footballmania; RIBEIRO. A bola em meio a ruas alinhadas e a uma poeira infernal.
} 
No Oeste mineiro, tais reações, permeadas pelas simbologias da competitividade, implicaram o acirramento das tensões sociais. Decorre-se daí que as comitivas que participavam de encontros intermunicipais nem sempre preservavam o clima amistoso que se almejava para os esportes. Em setembro de 1925, acerca do encontro realizado entre o 201 Foot Ball Club, da cidade Oliveira, e o Sport Club Claudiense, da cidade de Cláudio, um cronista da imprensa de Oliveira relatou os lances de "violência" da partida: "Notamos de parte a parte que os jogadores se preocuparam mais com a conquista de pontos, que com o modo de se conduzirem entre os seus companheiros. Daí a razão de alguns terem se machucado, por que o jogo teve alguns lances de extrema violência".47 Já no encontro realizado na cidade de Itapecerica, entre o Bom Sucesso Foot Ball Club e o São Bento Foot Ball Club, em julho de 1927, outro cronista da imprensa de Oliveira descreveu os "vários incidentes":

\begin{abstract}
A pugna teve início pouco depois das 15 horas, estando o campo repleto de torcedores, achando-se presente a banda Santa Cecília. Serviram de juízes no 1o e no $2^{\circ}$ tempo respectivamente os Srs. Severo Reis e seu irmão cujas atuações foram muito infelizes, dando lugar a vários incidentes. No 1o tempo o juiz anulou injustamente um ponto conquistado pelo team visitante. Quase no fim da pugna, a equipe bomsucessense conseguiu vazar novamente o goal adversário. Tendo o juiz continuado o jogo, quando estava terminado o tempo, apesar dos protestos da embaixada de B. Sucesso e de seus torcedores, o S. Bento uns 10 minutos após conseguiu o seu primeiro e único tento. [...] 0 juiz considerou o jogo empatado. ${ }^{48}$
\end{abstract}

As transformações que incluíram nos jogos de foot-ball novos elementos, como violência, incidentes e protestos, foram alvo de críticas por parte dos sportmen divinopolitanos. Se, na "assistência" da cidade, o caráter combativo dos encontros adquiria maior apelo, evidenciado em junho de 1923 quando o arremate de um "hands", ao vazar o posto do goleiro belorizontino, foi, nas palavras de um cronista, comemorado "debaixo dos frenéticos aplausos dos assistentes",49 no interior do clube União, os sócios, seguindo na contramão da nova tendência, buscaram manter o jogo com seu perfil cortês e agregador.

\footnotetext{
${ }^{47}$ GAZETA DE MINAS. Oliveira, p. 1, 4 outubro 1925.

${ }^{48}$ GAZETA DE MINAS. Oliveira, p. 2, 31 julho 1927.

${ }^{49}$ A ESTRELLA DA OESTE. Divinópolis, p. 5, 29 julho 1923.
} 


\section{A PERMANÊNCIA DOS SENTIDOS DE FIDALGUIA DO FOOT-BALL EM DiVINÓPOLIS}

Em março de 1925, era esperada na estação ferroviária de Divinópolis a comitiva esportiva do Cajuru Foot Ball Club, do pequeno distrito homônimo, para a realização de uma partida intermunicipal contra o clube União. ${ }^{50}$ No entanto, diferentemente dos encontros amistosos dos anos anteriores, o acirramento da disputa esportiva consolidava uma nova tendência para o jogo, que adquiria gradativamente significados completamente distintos daqueles criados pelos primeiros sportmen. Em sua cobertura do evento, um cronista de Divinópolis provê valiosos indícios de como o "partidarismo cego" e a "vitória desportiva" direcionava os jogos de foot-ball em diferentes pontos do interior mineiro, para "inimizades", "insultos" e "cenas indecorosas":

O foot-ball, que foi criado na velha Britânia tão somente para a cultura física e espiritual, infelizmente como sport, cá por estas plagas do interior, não tem passado de instrumento perigoso e móvel de cenas indecorosas, trazendo quase sempre inimizades torpes entre povos de uma e outra cidade. Já por diversas vezes, temos visto que um match de foot-ball é um espetáculo estupido em que vemos a paixão nos seus maiores tramites, explodindo imoralidades e ejaculando uma tempestade de insultos anavalhantes e mofas da parvoíce arruaceira. Já tantíssimas vezes temos também visto que a disputa de uma partida de foot-ball é um festim obsceno e indesejável, em que presenciamos a discórdia bifurcando a grandiosa obra da paz. Tudo porque? Por esta verdade Porque os adeptos do desporto, esquecendo-se das boas normas da educação, se entregam de corpo e alma, ao partidarismo cego, não sabendo que todos, amigos ou adversários na luta, devem receber o mesmo grau de simpatia e consideração, pois é nenhum o valor da vitória desportiva. Se todos pensassem na responsabilidade que um povo tem ao receber outro, para uma partida de football, ou se todos procedessem nas raias da educação, cremos nós, talvez um match de foot-ball fosse bom para o estreitamento de laços entre uma e outra gente.

Atualmente, depois que o brasileiro patenteou em ser politiqueiro em tudo, temos até medo quando chega ao nosso conhecimento que aqui se vai ferir um embate do celebre jogo bretão, pelo simples fato de querermos a nossa cidade livre de ser apontada por outra coirmã como um centro de estupidarrões e boçais, sem trato e compostura. ${ }^{51}$

Ao ver no foot-ball um mecanismo de "inimizades torpes entre povos", o cronista da nota evidencia como o partidarismo, a competitividade e o alargamento do interesse de "assistentes" permeavam os encontros intermunicipais no decorrer da década de 1920, com elementos novos e

\footnotetext{
${ }^{50}$ A ESTRELLA DA OESTE. Divinópolis, p. 2, 15 março 1925.

${ }^{51}$ A ESTRELLA DA OESTE. Divinópolis, p. 2, 22 março 1925.
} 
conflituosos. Assim, diferentemente das críticas que ele apresenta, na disputa em Divinópolis entre o clube União e o clube Cajuru, o clima de paz entre os sportmen recebeu elogios por parte da imprensa local: "Felizmente, domingo passado ficamos surpreendidos e satisfeitos, sobremodo, pois, o jogo que aqui se desenrolou entre o Cajuru e o União não deixou transparecer nada de desavença, ao contrário, foi festivo e alegre, sendo sua cor a da paz".52

À medida que o fenômeno do partidarismo que se disseminava nos embates futebolísticos promovidos por diversas comitivas esportivas do interior mineiro passava a ser condenado por cronistas da imprensa divinopolitana, por transformar o foot-ball em um "festim obsceno", os envolvidos com a prática institucional do jogo de bola em Divinópolis se mostravam decididos em manter a modalidade com um perfil cavalheiresco e capaz de promover o estreitamento das relações inter-regionais. Na partida que terminou com a vitória do clube União sobre o clube Cajuru pelo placar de 4 x 0, um cronista da imprensa de Divinópolis relatou as festividades e as múltiplas articulações promovidas pelos sócios das duas comitivas após o jogo:

Às 6 horas, regressaram a sua terra os cajuruenses, numa troca amistosa de vivas, levando uma boa impressão da modesta recepção que lhes deu o nosso povo. A noite realizou-se o baile oferecido pelo União ao Cajuru. 0 baile correu bem e foi bastante concorrido. Terminando esta ligeira notícia, felicitamos a diretoria e os jogadores do União pela maneira brilhante com que se houveram, esperando que, para outras festas vindouras, procedam sempre assim, para o bom nome e o melhor conceito da nossa terra. Aos cajuruenses, que tantas saudades nos deixaram, levamos os nossos abraços, pelo modo distinto e cavalheiresco que tiveram para conosco, esperando que perdoem faltas que, porventura, os divinopolitanos tenham praticado. ${ }^{53}$

Em meio a toda hospitalidade, no mês seguinte, uma festa "dentro da melhor camaradagem" foi organizada pelos anfitriões do clube Cajuru. ${ }^{54}$ Em abril de 1925, desembarcava naquela localidade a comitiva do União Foot Ball Club, que foi recebida com fogos, banda de música e discursos proferidos pelo farmacêutico José Maria Campos. Inserido em uma nova fase, o encontro evidenciou como o jogo de bola adquiria uma expansão do pertencimento clubístico entre os aficionados divinopolitanos: "Domingo passado, pelo trem da carreira partiram daqui a

\footnotetext{
${ }^{52}$ A ESTRELLA DA OESTE. Divinópolis, p. 2, 22 março 1925.

${ }^{53}$ A ESTRELLA DA OESTE. Divinópolis, p. 2, 22 março 1925.

${ }^{54}$ A ESTRELLA DA OESTE. Divinópolis, p. 3, 14 abril 1925.
} 
embaixada, os defensores e um grande número de torcedores do União F. C.”. Além da presença da torcida, os aspectos técnicos do jogo receberam maior espaço na cobertura feita por um cronista de Divinópolis:

\begin{abstract}
A partida de foot-ball foi interessante e cheia de lances sugestivos.
$\mathrm{O}$ team do União esteve em um de seus melhores dias: desenvolveu um jogo inteligente, seguro e certeiro. Os seus dianteiros estiveram excelentes, com exceção de Quito que foi infeliz nas suas escapadas. A linha de halfs esteve péssima e jogou pedra em santo. 0 trio defensivo sob a guarda de Vicente, Polycarpo e Mariano esteve supimpa e garantiu a vitória. 0 team do Cajuru apesar de forte e treinado, esteve infelicíssimo, jogando com uma urucubaca baita. A sua defesa esteve irregular e resistiu ao assédio dos fowards divinopolitanos. Os seus avantes fraquejaram no meio da partida e perderam boas ocasiões para o aumento da contagem de pontos. A cidadela do Cajuru foi vazada 4 vezes; a do União, uma vez, proveniente de uma scrimage na porta do goal. 0 árbitro do jogo foi correto e prudente. ${ }^{55}$
\end{abstract}

Apesar de apresentar um perfil mais competitivo, os cerimoniais de "praxe" dos jogos cavalheirescos da fase anterior mantinham-se predominantes. Segundo um cronista, os sportmen das duas comitivas realizaram diversos passeios pela região central de Cajuru, visitando a Igreja Matriz e muitas casas de famílias conhecidas, tomaram vários copos de cerveja e, antes do regresso dos divinopolitanos, foi oferecida aos sócios do clube União uma "mesa" na residência do Sr. Alfredo Mattar. ${ }^{56}$ Assim, por meio de diversas festividades pomposas, algumas delegações esportivas do Oeste mineiro relutavam em aderir ao novo perfil do jogo, que priorizava a competitividade e a vitória esportiva em detrimento da integração das elites envolvidas com o foot-ball.

É no cenário em que a cordialidade para com os adversários começava a sofrer algumas alterações, que os sócios do clube União decidiram interromper suas atividades e extinguir a única "embaixada" futebolística do meio local. Mesmo que alguns encontros já estivessem programados para ocorrer em julho de 1925, contra alguns congêneres vizinhos, como o "Cajuru F. C. de Cajuru; Americano F. C. de Pará de Minas, e um combinado de Belo Horizonte",57 as notícias sobre o jogo de bola desapareceram das colunas jornalísticas em Divinópolis. Pode ser que tais transformações sofridas pelo jogo foram determinantes para arrefecer o entusiasmo dos sportmen divinopolitanos, que diferentemente da tendência de

\footnotetext{
${ }^{55}$ A ESTRELLA DA OESTE. Divinópolis, p. 2-3, 19 abril 1925.

${ }^{56}$ A ESTRELLA DA OESTE. Divinópolis, p. 2-3, 19 abril 1925.

${ }^{57}$ A ESTRELLA DA OESTE. Divinópolis, p. 4, 12 julho 1925.
} 
competitividade, pertencimento clubístico e rivalidades, buscavam manter a modalidade dentro do contexto da boa educação esportiva.

Entre agosto de 1925 e novembro de 1927, os jogos de foot-ball em Divinópolis sucumbiram à falta de interesse de seus adeptos em organizar novos clubes. No entanto, o esporte bretão, enraizado e ramificado na sociedade divinopolitana, sinalizava que não se tornaria uma modalidade em risco de extinção. Em novembro de 1927, a Câmara Municipal enviou alguns de seus funcionários para iniciarem o "serviço de desaterro do campo do Divinopolis Foot Ball Club". ${ }^{58}$ Um Termo de Audiência da Câmara Municipal de Divinópolis, datado de 25 de novembro de 1927, oferece um interessante relato sobre os trabalhos realizados no campo:

O sr. Agente Municipal respondeu que durante a semana esteve fiscalizando e auxiliando no serviço de desentupimento das caixas de água da parte velha, e, depois deste serviço, os trabalhadores da Câmara achavam-se prosseguindo no serviço do campo de Foot-Ball e no de extinção de formigueiros. ${ }^{59}$

As obras no campo ocorreram simultaneamente à reorganização do Divinopolis Foot Ball Club, que se impunha novamente como uma comitiva capaz de promover atividades esportivas na cidade. ${ }^{60}$ Formado por vários remanescentes do clube União, os sócios do novo clube Divinopolis buscaram manter a fidalguia do clube anterior. Sua diretoria, eleita no final de dezembro de 1927, por meio de uma assembleia geral, foi constituída de agentes de grande prestígio social, entre eles: Ataliba Lago (jornalista), Orozimbo Silva (comerciante e adjunto do promotor de justiça), Mariano Biondini (delegado de polícia) ${ }^{61}$ e José Rufino de Abreu (diretor da Secretaria Municipal). ${ }^{62}$

O retorno das experiências com o fenômeno futebolístico logo motivou o surgimento de novas comitivas, dando mostras de como o jogo que se manteve desde a sua introdução restrito a um seleto grupo de sportmen passava por uma considerável intensificação de atividades. Em janeiro de 1928, um cronista local

\footnotetext{
${ }^{58}$ Termo de Audiência da Câmara Municipal de Divinópolis do dia 18 nov. 1927.

${ }^{59}$ Termo de Audiência da Câmara Municipal de Divinópolis do dia 25 nov. 1927.

${ }^{60}$ A ESTRELLA D' OESTE. Divinópolis, p. 1, 4 dezembro 1927.

${ }^{61}$ Cf. A ESTRELLA D' OESTE. Divinópolis, p. 2, 4 outubro 1925.

${ }^{62}$ Cf. CRISPIM. Atos dos presidentes e vereadores da Câmara Municipal de Divinópolis, p. 22.
} 
relatou uma disputa entre o Divinopolis Foot Ball Club e o recém-fundado Brasil Foot Ball Club:

Realiza-se hoje, às 2 horas da tarde, o esperado encontro entre o $2^{\circ}$ quadro do Divinopolis e o $1^{\circ}$ do Brasil F. C., novel e futurosa sociedade desportiva desta cidade. É uma partida que esta despertando vivo interesse nas nossas rodas desportivas. Antes do jogo haverá posse solene da nova diretoria do Divinopolis F. C. ${ }^{63}$

Ainda em 1928, outro cronista relatou a fundação de uma nova comitiva, formada, sobretudo, por remanescentes do extinto clube Internacional:64

\section{AMERICA SPORT CLUB}

Os antigos elementos do Internacional F. C., a vitoriosa sociedade desportiva que aqui existiu, acabam de fundar nesta cidade o America Sport Club, nova agremiação desportiva fadada a um futuro brilhante graças ao concurso de SPORTMAN Joaquim Berreca, Constante Silva e tantos outros. ${ }^{65}$

Se por um lado via-se o ressurgimento de atividades envolvendo clubes esportivos dedicados ao jogo de bola, por outro, as novas agremiações reafirmavam o perfil refinado que caracterizou os clubes pioneiros. Em janeiro de 1928, um cronista anunciava a visita de uma delegação esportiva de Belo Horizonte:

No próximo dia 8 de janeiro corrente, virá a esta cidade para jogar uma partida com o Divinopolis F. C., a Valente Sociedade Athletica João Pinheiro, agremiação de grande conceito no desporto de Belo Horizonte.

Dado ao valor do clube visitante, composto de lúrida mocidade, a festa sportiva do dia 8 promete revestir-se de grande entusiasmo. ${ }^{66}$

A capacidade de organização de uma festa esportiva, com uma "agremiação de grande conceito" da capital mineira, revela como o jogo ainda congregava entre seus praticantes os agentes das camadas mais abastadas. Além da seleção refinada, o caráter polido e cavalheiresco dos encontros também remetia aos sentidos que foram construídos pelos primeiros sportmen. No "encontro amigável", realizado em novembro de 1928, na cidade de Oliveira, entre o Brasil Foot Ball Club de Divinópolis e seu homólogo daquela localidade, ${ }^{67}$ a cordialidade e a boa educação esportiva do encontro foram destacadas por um cronista da imprensa divinopolitana:

\footnotetext{
${ }^{63}$ A ESTRELLA D' OESTE. Divinópolis, p. 1, 1 janeiro 1928.

${ }^{64}$ Não encontramos nos periódicos cotejados informações acerca do clube Internacional.

65 GAZETA POPULAR. Divinópolis, p. 3, 9 dezembro 1928.

${ }^{66}$ A ESTRELLA D' OESTE. Divinópolis, p. 1, 1 janeiro 1928.

${ }^{67}$ GAZETA DE MINAS. Oliveira, p. 1, 11 novembro 1928.
} 
Domingo passado partiu daqui a embaixada do BRASIL F. C. com destino a cidade de Oliveira, onde foi disputar uma partida de foot-ball com o seu homônimo oliveirense.

Na gare da estação de Oliveira, os divinopolitanos foram saudados pelo $\mathrm{Sr}$. Ouvidio Chagas, secretário do clube oliveirense. Respondeu-lhe saudando o povo de Oliveira, o redator desta folha. ${ }^{68}$

0 jogo foi realizado em disputa da Taça Dr. Djalma Pinheiro Chagas.

Tanto o Brasil daqui como o Brasil da vizinha cidade, fizeram um jogo a altura, debaixo da melhor cordialidade.

0 resultado da peleja foi um empate honroso de $3 \times 3$.

0 trato dispensado aos divinopolitanos foi o melhor possível o que demonstra a boa educação esportiva do povo de Oliveira. ${ }^{69}$

Enquanto, em algumas localidades da região, o jogo de bola, no decorrer da década de 1920, passava por uma ampla expansão socioespacial, fazendo com que, já no primeiro ano da década de 1930, o valor combatido, o pertencimento clubístico e as rivalidades consolidassem uma nova dinâmica aos encontros, ${ }^{70} \mathrm{em}$ Divinópolis, a prática institucional do jogo permanecia restrita a um seleto grupo, fato que foi determinante para a manutenção do caráter fidalgo envolvendo os espetáculos esportivos. A tendência de camaradagem, na qual o jogo, em vez das rivalidades, transformava-se em um forte laço entre os sportmen divinopolitanos, foi demonstrada na participação ativa do jornalista Ataliba Lago nas comitivas locais. Além de ocupar o cargo de presidente do Divinopolis Foot Ball Club e viajar para Oliveira com a comitiva do Brasil Foot Ball Club, o jornalista também ocupava o cargo de "presidente honorário" do America Sport Club:

Ilmo. Sr. Ataliba Lago

De ordem do Sr. Presidente do America Sport Club, tenho a honra de comunicar-vos, que em reunião realizada no dia três do corrente mês, fostes eleito presidente honorário deste club.

${ }^{68}$ Cabe destacar que o redator e proprietário do jornal Gazeta Popular, era o jornalista Ataliba Lago, que assumiu o papel de orador do clube Brasil na pugna realizada na cidade de Oliveira. Cf. CORGOZINHO; PIRES; CATÃO. Jornais editados em Divinópolis durante a $1^{\underline{a}}$ metade do séc. XX, p. 280.

${ }^{69}$ GAZETA POPULAR. Divinópolis, p. 2, 11 novembro 1928.

${ }^{70} \mathrm{Na}$ cidade de Oliveira, por exemplo, na ocasião do encontro esportivo entre o Sparta Sport Club e o Atlhetico Sport Club, ambos daquela localidade, programado para ocorrer em julho de 1930, um cronista do jornal Gazeta de Minas publicou uma entrevista com um membro da diretoria do Sparta, cujo conteúdo deixa transparecer uma forte rivalidade entre os dois clubes: "Os nossos dois quadros entrarão em campo com uma vontade ferrenha de vencer. Nunca tive tanta vontade de derrotar um adversário como estou [...] O que mais posso adiantar aos apreciadores de tão nobre sport bretão é que entraremos em campo convictos da vitória e pela glória do nosso Sparta, bateremos com ardor e entusiasmo". Para uma síntese da consolidação dos sentidos de competitividade do foot-ball na cidade de Oliveira, ver AMARAL; COUTO. "Um festin obsceno": pertencimento clubístico e expansão socioespacial do foot-ball em Oliveira-MG (1920-1930). 
Sem outro motivo, subscrevo-me - o secretário do America Sport Club CONSTANTINE SILVA. Divinópolis 06-12-1928. ${ }^{71}$

Dessa forma, o foot-ball em Divinópolis, mesmo com mais clubes, permanecia sobre as rédeas do cavalheirismo e da boa educação. Em agosto de 1930, encontramos na imprensa divinopolitana as primeiras referências acerca do União Athletico Club, comitiva que, no dia 20 do mês anterior, havia promovido uma festa esportiva para coroar a Rainha e Madrinha do clube, evento marcado por uma disputa intermunicipal entre o quadro local e o São Bento Sport Club da cidade de Itapecerica. Mesmo com a derrota pelo placar de 2 x 0 para os visitantes, os anfitriões ofereceram diversas atrações lúdicas aos sócios do clube São Bento e pessoas da "melhor sociedade" divinopolitana:

Foi oferecido aos itapecericanos visitantes uma sessão cinematográfica, a que compareceu grande número de pessoas, cujo beneficio se converteu em favor do União Athletico Club.

$\mathrm{Na}$ noite de domingo realizou-se no Grêmio Literário, a coroação da Rainha e Madrinhas do Club, respectivamente as senhorinhas Ana Lucchesi, Maria Botelho e Maria da Conceição Silva, que foram saudadas pelo vice-presidente do Club, Francisco Gontijo Neto, que pronunciou vibrante alocução oratória, pelo que foi muito aplaudido.

Responderam as senhorinhas Ana Lucchesi e Maria Botelho. Foi uma sessão animadíssima, na qual compareceram elementos da nossa melhor sociedade e da sociedade de Itapecerica. ${ }^{72}$

Essa nota reforça a hipótese de que a prática institucional do foot-ball em Divinópolis permaneceu ao longo de toda a década de 1920, com um perfil cavalheiresco e restrito institucionalmente a um seleto grupo de sócios. Apenas a partir dos primeiros anos da década de 1930, os atributos de competitividade tiveram centralidade e o jogo se expandiu institucionalmente entre as camadas menos abastadas, dando mostras de como o processo de reconstrução dos sentidos criados pelos clubes pioneiros apresentou múltiplas variáveis, não ocorrendo de forma homogênea em toda região.

\footnotetext{
${ }^{71}$ GAZETA POPULAR. Divinópolis, p. 3, 9 dezembro 1928.

72 A PENA. Divinópolis, p. 1-2, 1 agosto 1930.
} 


\section{CONSIDERAÇõES FINAIS}

0 cotejamento das fontes primárias arroladas neste artigo permite constatar que o processo de implantação do foot-ball na cidade de Divinópolis foi fruto das ações promovidas por um "seleto" grupo de sócios da comitiva do Divinopolis Foot Ball Club, que logo tomaram as rédeas institucionais da modalidade. Na mesma época, o jogo se estendia pelas rodas mais abastadas de diversas outras localidades do Oeste mineiro, favorecendo a realização de encontros intermunicipais que promoviam o estreitamente de laços políticos e sociais dos grupos envolvidos com comitivas esportivas.

Na cidade de Divinópolis, a construção de redes de sociabilidades e de cooperação política, originadas nos encontros futebolísticos, foi determinante para que os seletos sportmen divinopolitanos buscassem, no decorrer de toda a década de 1920, manter o esporte como um elemento de fidalguia, permeado por atributos de civilidade e cavalheirismo. Não por acaso, em 1925, quando o afloramento do "valor combativo" imiscuía nos encontros intermunicipais novos predicados como "violência", "incidentes" e "protestos", os sócios do clube União enceraram suas atividades. Mesmo que os últimos anos da década de 1920 tenham sido marcados em Divinópolis pelo retorno das experiências com o fenômeno futebolístico e de sua expansão clubística, o jogo ainda permaneceu sob as rédeas do "cavalheirismo" e da "boa educação".

Assim, longe de ocorrer como um processo homogêneo em toda região, desvelaram-se diversos aspectos que indicam que a cidade de Divinópolis vivenciou de forma singular a difusão da prática institucional do foot-ball. Embora as abordagens apresentadas neste artigo possuam caráter introdutório, elas sugerem a abertura de uma multiplicidade de caminhos analíticos que ainda podem ser percorridos no sentido de elucidar os aspectos socioculturais sobre a inserção e difusão do jogo em regiões afastadas dos grandes centros do país. Somente com a produção de novas investigações será possível encontrar elementos inéditos referentes ao período embrionário do foot-ball e sua inserção no cotidiano dos habitantes de localidades do interior, com vistas a evidenciar as peculiaridades dos processos de difusão do jogo de bola em diferentes regiões do país. 


\section{REFERÊNCIAS}

AMARAL, Daniel Venâncio de Oliveira; COUTO, Euclides de Freitas. "Um festin obsceno": pertencimento clubístico e expansão socioespacial do foot-ball em Oliveira-MG (1920-1930). Fênix - Revista de História e Estudos Culturais, v. 14, n. 1, jan.-jun. 2017, p. 1-19.

AMARAL, Daniel Venâncio de Oliveira; DIAS, Cleber. Nos trilhos do lazer: entretenimento urbano e mercado de diversões em Divinópolis, Minas Gerais, 1890-1920. Revista de História Regional, Ponta Grossa, v. 22, n. 2, jul.-dez. 2017, p. 237-261.

CORGOZINHO, Batistina Maria de Souza. Nas linhas da modernidade: a passagem do tradicional ao moderno no centro-oeste de Minas Gerais. Divinópolis, MG: FUNEDI, 2003.

CORGOZINHO, Batistina Maria de Souza; PIRES, João Ricardo Ferreira; CATÃO, Leandro Pena. Jornais editados em Divinópolis durante a $1^{a}$ metade do séc. XX. In: CATÃO, Leandro Pena; PIRES, João Ricardo Ferreira; CORGOZINHO, Batistina Maria de Souza (org.). Divinópolis: história e memória. V. 2: Política e Sociedade. Belo Horizonte: Crisálida, 2015, p. 267-316.

COUTO, Euclides de Freitas; SILVA, Sabrina Alves da. Circularidade cultural e modernização dos hábitos: o modelo clubístico do Athletic Club, em São João del-Rei/MG (1909-1925). Tempos Gerais, São João del-Rei, v. 3, n. 2, jan.-jun. 2014, p. 123-136.

CRISPIM, Marcos Antônio Vilela. Atos dos presidentes e vereadores da Câmara Municipal de Divinópolis: de 1912 a 1945. Divinópolis: Gráfica Divinópolis, 2001.

DIAS, Cleber. Esporte e cidade: balanços e perspectivas. Revista Tempo, v. 17, n. 34, jan.-jun. 2013, p. 33-44.

DIAS, Cleber; SOUZA NETO, Georgino J. de; SILVA, Igor M. da; MAYOR, Sarah S. História do futebol em Minas Gerais. Tempos Gerais, São João delRei, v. 3, n. 2, jan.-jun. 2014, p. 67-86.

LIMA, Alex Witney. Trilhas históricas do Foot-Ball em São João del-Rei: os clubes, as ligas e os campeonatos (1909-1921). Tempos Gerais, São João del-Rei, v. 3, n. 2, jan.-jun. 2014, p. 105-122.

MELO, Victor Andrade de (org.). Os sports e as cidades brasileiras: transição dos séculos XIX e XX. Rio de Janeiro: Apicuri, 2010.

MINAS GERAIS. Secretaria da Agricultura. Annuario estatistico: anno I (1921), v. II, III, IV. Belo Horizonte: Imprensa Oficial, 1926.

MINAS GERAIS. Secretaria das Finanças. Relatório apresentado ao Exmo. Sr. Dr. Raul Soares de Moura. Belo Horizonte: Imprensa Oficial, 1923.

PEREIRA, Leonardo Affonso de Miranda. Footballmania: uma história social do futebol no Rio de Janeiro, 1902-1938. Rio de Janeiro: Nova fronteira, 2000. 
RAPOSO, Mauro Corgozinho. Dicionário dos construtores de Divinópolis. Divinópolis: Express, 2001.

RIBEIRO, Raphael Rajão. A bola em meio a ruas alinhadas e a uma poeira infernal: Os primeiros anos do futebol em Belo Horizonte (1904-1921). 2007. Dissertação (Mestrado em História) - Faculdade de Filosofia e Ciências Humanas da Universidade Federal de Minas Gerais, Belo Horizonte, 2007.

Recebido para publicação em: 03 out. 2017. Aprovado em: 9 dez. 2017. 